\title{
Electrical, Civil, and Mechanical Engineering
}

\section{Dr. David Clippinger, The Pennsylvania State University, Erie-The Behrend College}

Dr. David Clippinger is a faculty member in Mechanical Engineering Technology at the Pennsylvania State University, Erie-the Behrend College. His interests are ship dynamics, measurement \& instrumentation, and assessment, especially of student writing.

\section{Dr. Steven Y. Nozaki, Penn State Erie, The Behrend College}

Ph.D. Engineering Education - The Ohio State University

\section{Dr. Kathleen Jernquist, United States Coast Guard Academy}

Kathleen Jernquist retired as the director of the Hewitt Writing Center at the U.S. Coast Guard Academy. She earned her M.A. from Middlebury College and her Ph.D. from Brown University. 


\title{
Using Common Language to Identify Discipline-specific "Dialect” in Electrical,
} Civil, and Mechanical Engineering

\author{
David C. Clippinger, Pennsylvania State University, Erie \\ Steven Y. Nozaki, Pennsylvania State University, Erie \\ Kathleen Jernquist, US Coast Guard Academy
}

\begin{abstract}
:
While the importance of being able to communicate effectively in writing is widely understood, nevertheless there are persistent differences between the writing styles of students and professionals working in the same discipline. This work further explores a hypothesis by the authors that the presence of distinct written "dialects" in different engineering communities is a source of mixed messages for students, who can be confused by the often-conflicting writing advice presented in various core and discipline-specific courses. Quantitative methods verified this hypothesis, as the results show that author voice, development, style, and diction vary significantly between electrical, civil, and mechanical engineering journal articles. As a result, neither the "STEM writing style" nor the "Engineering writing style" can be considered to be a homogeneous entity. Equipped with this awareness, those personnel responsible for teaching writing to undergraduate students can hopefully be more effective in the delivery of their instruction. Extensions which propose the investigation of engineering writing style among nonacademic practitioners and students are included.
\end{abstract}

\section{Introduction:}

The importance for engineering, engineering technology, and science majors was discussed in an earlier work [1], and will be reviewed very briefly here for convenience and completeness.

Arguably the most important governing document for technical program curricula, ABET's accreditation criteria regard effective communication and awareness of audience to be essential disciplinary knowledge, as reflected in the outcomes for applied science, engineering technology, and engineering programs:

- an ability to communicate effectively with a range of audiences [2]

- an ability to apply written, oral, and graphical communication in broadly-defined technical and non-technical environments; and an ability to identify and use appropriate technical literature [3]

an ability to communicate effectively with a range of audiences [4]

The reader is referred to an earlier work by the authors [1], where it is shown that similar wording appears in guidance for mathematics and other scientific disciplines. 
However, despite this near universal emphasis on the importance of communication skills for STEM students, works such as those by Boettger and Wulff [5] and Wolfe [6] identify differences between the written style of professionals working in student's disciplines and that of the students themselves. Attempts by engineering faculties to address this persistent gap have included collaboration with writing centers [7] and communication-specific courses populated by personnel with knowledge of engineeringspecific writing to help develop the various effective communication outcomes to the level expected by the profession [8]. Collaboration among faculty in undergraduate engineering technology, engineering, and writing programs has also been employed to help satisfy ABET criteria and to facilitate the improvement of the complicated process of learning to write in one's profession [9], [10].

Beaufort has identified the "five domains of writing knowledge,"-- genre, discourse community, process, content, and rhetorical --which are incorporated among writing centers, courses, and similar venues in support of disciplinary writing to [11]. The process of student incorporation of writing skills with technical content is typically gradual, and Artemeva [12] has identified the third year of undergraduate study as the time when content and rhetorical knowledge "begin to merge." Devitt [13] has identified the various forms of written work submitted in the course of an undergraduate engineering program-forms such as lab reports, design reports, and the like - as the means through which students develop the skills to integrate the rhetorical with the technical.

The present work focuses on sentence-level expression in technical writing. Works such as those by Swales [14] and [15] discuss various techniques designed to facilitate appropriate development of this skill among students in technical disciplines. Smit [16] discusses research-based methods to foster the ability of students to transfer knowledge between core and discipline-specific courses. However, ultimately developing what Bazerman calls "the meaning making aspects of writing" in a new discipline's system of writing [17], requires considerable investment in resources on the part of an undergraduate program.

Work has been done to better identify the "code" or "dialect" that is used in a specific sub-genre of engineering writing: the academic journal [1]. Written works in the field of mechanical engineering were compared with selections from the natural sciences in search of subtle differences in dialect. Informed by the work of Robert Irish [18], data and analyses of style and verb use, voice and pronoun use, and development via use of extended prose or visuals show significant variation in "technical writing." The findings can support faculty in identifying nuances of expression, articulating expectations in writing assignments and assessments, and guiding upper-class undergraduates to develop professional-level expression.

The goal of the current project is to better identify the codes and dialects among engineering disciplines: specifically, civil, electrical, and mechanical engineering. Research questions guiding this work are:

In what ways can using a rhetorical language to analyze the professional writing of engineers reveal discipline-specific codes and dialects*? 
How can teaching engineering majors a rhetorical language with which to analyze the writing expected of them support them in developing strategies to communicate effectively?

*The authors recognize that the term "dialect" usually applies to spoken language, and "code" or "register" to written forms. Sometimes the term "diatype" is used describe the concepts of dialect and register without regard to spoken vs. written delivery. However, in an effort to make this work as accessible as possible to engineering professionals who have limited exposure to such terminology, the word "dialect" will be used throughout this work in its colloquial sense; e.g. a form of communication specific to a certain community.

\section{Methodology:}

The authors used quantitative methods to measure the dimensions of writing as described in the list shown in table 1. For the purpose of analysis, samples of journal articles from recent volumes of IEEE Access, ASCE's Journal of Structural Engineering (JOSE), ASME's Journal of Applied Mechanics $(J A M)$, and student work drawn from senior-level capstone design reports in a Mechanical Engineering Technology (MET) program at the authors' home institution.

Table 1: Rhetorical language used for analysis

\begin{tabular}{|l|l|}
\hline Dimension & Description \\
\hline Voice & Relationship of author to content \\
\hline Development & Method of presenting content \\
\hline Style & Author's technique \\
\hline Diction & Choice of words \\
\hline
\end{tabular}

The methodology for quantitatively measuring each of the four chosen dimensions is described below, and largely follows the same methodology as first presented in [1].

Voice:

Voice analysis was conducted to discover the presence of the author in the written work. The analysis was based on the use of first-person pronouns, the use of which indicates the presence of the author in the work. Works written in the third-person, or that refer to the authors in the third person, are indicative of a more detached, or impersonal voice. Here, the pronouns "I," "we" "our" and "us" were used to measure the presence of the author in the work. Student work was only available in paper form and therefore was only assessed for the presence of absence of pronouns.

\section{Development:}

Development refers to the manner in which the authors present content. As a quantitative metric of development, the percent of page area that was devoted to graphics (tables and graphs) as compared to prose was measured. The metric used was "centimeter of column length," and expressed as a percent of overall length. 
Development was also measured by the role in which numbered equations play in the presentation of content. Here, the number of indented equations in each work was simply counted and presented numerically.

Style:

Style, or author's technique, was analyzed through a quantification of the authors' use of verbs. To facilitate this, Irish's scale of verbs from [18] was adopted for use, and is reproduced here for convenience in table 2 as represented in [1].

Table 2: Scale of verbs from [18], reproduced with edits from [1]

\begin{tabular}{|c|c|c|c|c|c|}
\hline 1 & 2 & 3 & 4 & 5 & 6 \\
\hline $\begin{array}{l}\text { Active } \\
\text { imperative }\end{array}$ & $\begin{array}{l}\text { Active } \\
\text { conditional }\end{array}$ & $\begin{array}{l}\text { Gerunds and } \\
\text { infinitives }\end{array}$ & $\begin{array}{l}\text { Passive verbs, } \\
\text { passive } \\
\text { conditional }\end{array}$ & $\begin{array}{l}\text { Statement of } \\
\text { condition }\end{array}$ & Participles \\
\hline $\begin{array}{l}\text { The } \\
\text { experiment } \\
\text { proved the } \\
\text { result. }\end{array}$ & $\begin{array}{l}\text { The } \\
\text { experiment } \\
\text { could prove } \\
\text { the result. }\end{array}$ & $\begin{array}{l}\text { The goal is } \\
\text { proving (or to } \\
\text { prove) the } \\
\text { result. }\end{array}$ & $\begin{array}{l}\text { The result was } \\
\text { proven by the } \\
\text { experiment. }\end{array}$ & $\begin{array}{l}\text { The result is } \\
\text { negative. }\end{array}$ & $\begin{array}{l}\text { The } \\
\text { experiment's } \\
\text { result was a } \\
\text { proven } \\
\text { hypothesis. }\end{array}$ \\
\hline
\end{tabular}

Here, two paragraphs from the "introduction" section of each of the analyzed works were assessed. In each case, the excerpt was manually inspected, and notations were made to indicate the manner in which the verbs appeared in each sample. For example:

Here, two paragraphs from the "introduction" section of each of the analyzed \{6-participle\} works were assessed $\{4$-passive verb $\}$. In each case, the excerpt was manually inspected $\{4-$ passive verb , and notations were made $\{4$-passive verb $\}$ to indicate $\{3$-infinitive $\}$ the manner in which the verbs appeared $\{1$ - active imperative $\}$ in each sample.

The process continued until the end of the samples was reached, at which point a "search" feature was used to tabulate the total number of appearances of each verb form. These data were then expressed in percent form. For example, the excerpt analyzed above has six verbs, of which one is active, one is an infinitive, three are passive, and one is a participle. Hence, fifty percent of the verbs in the sample were passive.

Diction:

Diction was analyzed quantitatively by counting the use of words that can be described as "hedging," "boosting" or "attitude" words. Examples of each are provided in the list below, adapted from [1]:

Hedging words: about, almost, essentially, largely, mostly, possibly seemingly, suspected, uncertain, unclear

Boosting words: actually, always, certainly, clearly, definitely, never, obviously, undoubtedly, well-known

Attitude words: appropriately, disappointing, interestingly, preferably, understandably 
Words were found through an electronic search feature and counted based on the context in which they appeared. For example, the word "about" was considered to be a hedging word when its use in a sentence was essentially synonymous with "approximately." However, in other contexts, such as when used to describe a rotation, (a usage common in structural engineering, e.g. "a rotation about the axis") it was not considered to be a hedging word. A similar method was applied to the word "uncertainty," when can be used in the context of a measurement's expected level of accuracy ("measurement uncertainty"), where the use of the word is associated with a quantitative measure of the confidence in a measurement. In these cases the word "uncertainty" ironically connotes a greater precision in usage.

\section{Results:}

The results of each of the analyses are as follows:

Voice:

The presence of pronouns in each written example are summarized in table 3 .

Table 3: Instances of pronoun use by source of work

\begin{tabular}{|l|c|l|l|l|c|}
\hline Work & $\begin{array}{l}\text { Average } \\
\text { Instances of } \\
\text { "I" per work }\end{array}$ & $\begin{array}{l}\text { Average } \\
\text { Instances of } \\
\text { "we" per work }\end{array}$ & $\begin{array}{l}\text { Average } \\
\text { instances of } \\
\text { "Our" per } \\
\text { report }\end{array}$ & $\begin{array}{l}\text { Average } \\
\text { instances of } \\
\text { "Us" per } \\
\text { report }\end{array}$ & $\begin{array}{l}\text { Percent of } \\
\text { works with } \\
\text { personal } \\
\text { pronouns }\end{array}$ \\
\hline IEEE Access & 0.466 & 36 & 7.27 & 2.4 & $93 \%$ \\
\hline ASCE JOSE & 0 & 0 & 0 & 0 & $0 \%$ \\
\hline ASME JAM & 0 & 23 & 5.27 & 0.47 & $100 \%$ \\
\hline Student work. & -- & -- & -- & -- & $67 \%$ \\
\hline
\end{tabular}

Development:

The proportion of space dedicated to graphs and figures vs space for the different works assessed is provided in table 4 .

Table 4: Development statistics by work

\begin{tabular}{|l|c|c|c|}
\hline Work & $\begin{array}{l}\text { Portion of } \\
\text { space devoted } \\
\text { to charts and } \\
\text { figures }\end{array}$ & $\begin{array}{l}\text { Average } \\
\text { number of } \\
\text { equations }\end{array}$ & $\begin{array}{l}\text { Percent of } \\
\text { works with } \\
\text { any equation } \\
\text { at all }\end{array}$ \\
\hline IEEE Access & $17.2 \%$ & 3.5 & $40 \%$ \\
\hline ASCE JOSE & $37.8 \%$ & 17.9 & $100 \%$ \\
\hline ASME JAM & $32.6 \%$ & 21.3 & $100 \%$ \\
\hline Student work. & -- & -- & -- \\
\hline
\end{tabular}

Style:

Bar charts showing the relative appearance of the different verb forms for works in electrical, civil, and mechanical engineering appear as figures 1,2 and 3, respectively 


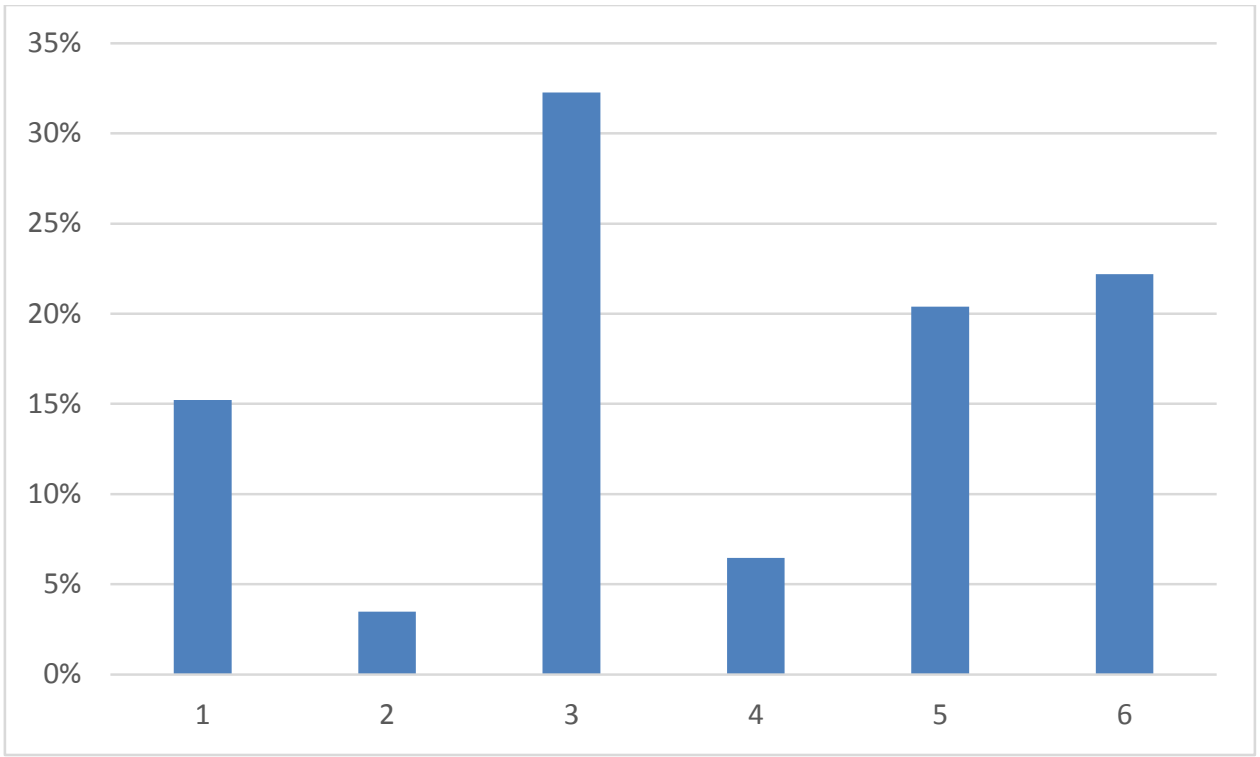

Figure 1: Relative frequency of verb type for IEEE articles

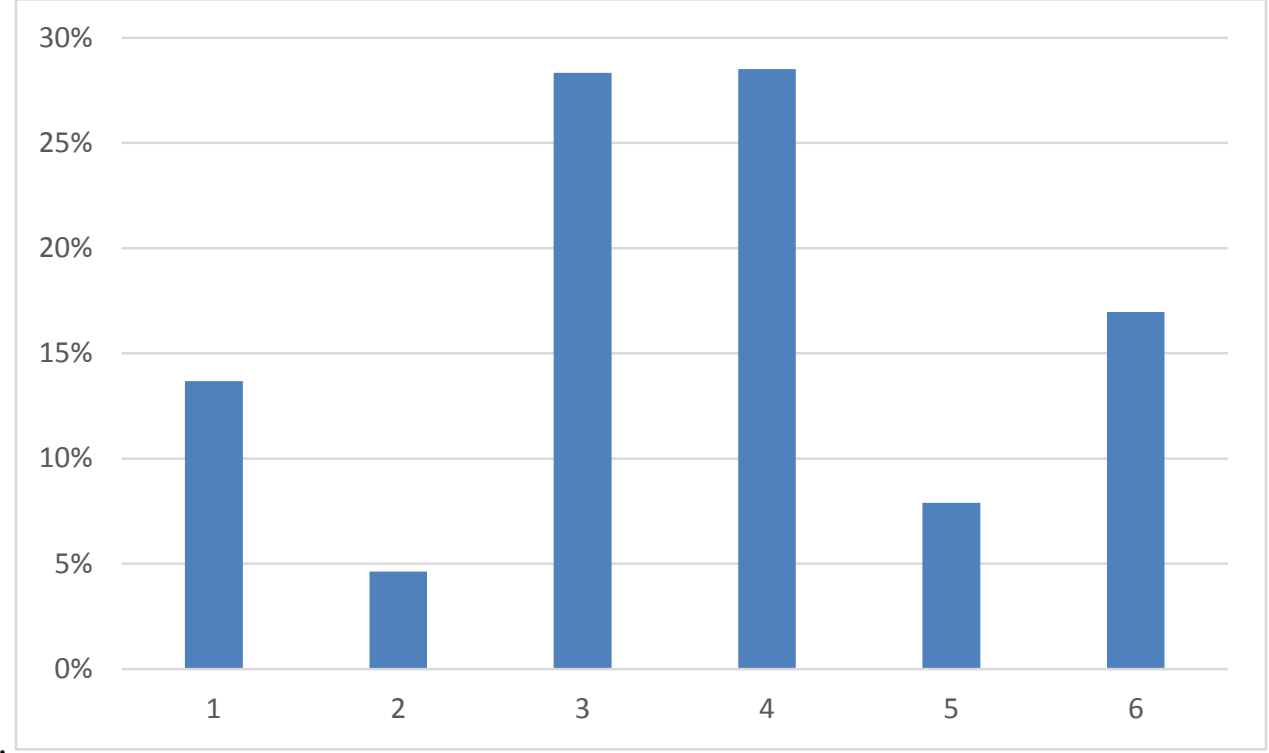

Figure 2: Relative frequency of verb types for ASCE Structural Engineering articles 


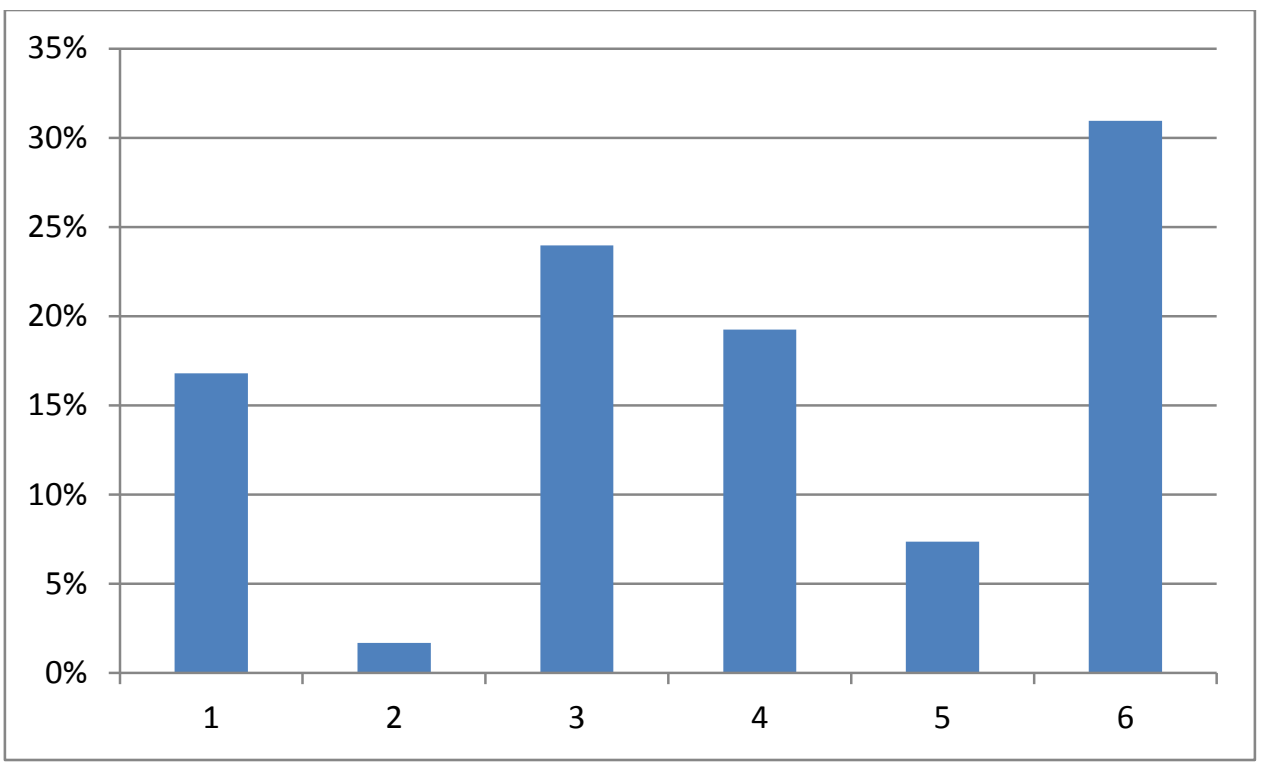

Figure 3: Relative Frequency of verb type for ASME articles

\section{Diction:}

The occurrence of hedging, boosting and attitude words in each of the types of works studies is shown in table 5 .

Table 5: Frequency of various forms of diction by discipline

\begin{tabular}{|l|c|c|c|}
\hline & \multicolumn{3}{|c|}{ Number of instances in 15 articles } \\
\hline Source articles & Hedging & Boosting & Attitude \\
\hline IEEE & 73 & 51 & 24 \\
\hline ASCE & 51 & 39 & 6 \\
\hline ASME & 190 & 65 & 3 \\
\hline
\end{tabular}

\section{Discussion:}

The results show significant differences between formal academic writing in the three disciplines studied. The most pronounced difference was the complete absence of author voice in the ASCE structural engineering articles. Not one instance of personal pronoun was found anywhere in the 15 papers reviewed. The ASME journal articles had an author presence in all fifteen papers reviewed, but the presence of the author voice was somewhat moderate; the pronoun "we" appeared an average of 23 times per paper, with "our" and "us" appearing significantly less often. In contrast, the IEEE articles had the greatest author presence, with personal pronouns appearing at the greatest frequency of the three disciplines. While one IEEE paper made use of no pronouns whatsoever, on average the sample set employed the use of pronouns at a rate 50\% than that used in the ASME papers.

In the development analysis, it was found that ASCE and ASME articles were similar in terms of their use of charts and figures - about one-third of total article space - and also employed a similar number of equations: a value in the high teens for ASCE and in the low 20's for ASME. This slight deficit in the number of equations in the ASCE papers is roughly offset by the presence of additional space devoted to charts and figures, making the relative contribution of prose approximately the same in the two disciplines. In contrast, the IEEE articles devoted significantly less space to figures (less than $20 \%$ of the 
entire paper), and had only a fraction of the number of equations: and average of only 3.5 equations per paper. Indeed, $60 \%$ of the IEEE papers had no equations at all.

The greater frequency of personal pronouns in the IEEE papers also evidenced itself in the authors' style. While ASME and ASCE showed relatively equal use of gerunds and infinitives, and ASCE showed the greatest use of all of passive verbs, the IEEE papers made relatively rare use of the passive (only $7 \%$ of verbs) and significantly greater use of statements of condition (verb form \#5). Both the ASCE and IEEE made much less use of participles than the ASME papers, where such words accounted for greater than $30 \%$ of all verbs.

Lastly, diction between the three disciplines showed significant deviation, with the ASME articles topping IEEE and ASCE papers in the use of boosting and hedging words. The use of hedging words was particularly pronounced; they appeared at a rate about 2.5 times higher than in IEEE articles and nearly four times as common as in the ASCE articles. In contrast, the IEEE articles made significantly greater use of attitude words; such words appeared at a rate four and eight times more frequently than in ASCE and ASME papers, respectively.

\section{Conclusion:}

Engineering writing--and by extension, STEM writing--is far from a homogeneous whole. As discussed in the introduction, the task of teaching students to "write like an engineer" consumes a significant amount of instructional resources, yet yields mixed results in terms of their effectiveness at teaching students to write within their academic major. The results of this work shed some light on one reason why this may be the case: "engineering writing" displays significant, measurable differences between disciplines, and a student in a, say, mechanical engineering program may prepare written work for courses taught by science faculty (physics courses), civil engineering faculty (statics, mechanics of materials), mechanical engineering faculty (dynamics, machine design), and electrical engineering faculty (electric circuits, controls). In each case, the student will be instructed the "right" way to write, only to be contradicted by their colleagues in other disciplines! As a result, the student will demonstrate a lack of progress in writing development unless he or she is able to reconcile this conflicting guidance.

As discussed in the introduction, a trained writing center "coach" can help the student navigate this conundrum. However, the writing center coach must be versed in the nuances of all the different disciplines in which he or she is expected to provide guidance. Such awareness of nuances begins with the careful cataloging of the characteristics of the writing styles in the different STEM disciplines, and this paper will hopefully serve as a useful first step.

As an extension, the authors propose a similar analysis of engineering writing from outside of the academic arena: government reports, patent filings, and internal corporate documents likely all have "dialects" distinct from those analyzed here. It will only be after an analysis of the variation in writing between the disciplines, and within the communities of each discipline (corporate, government, academic) that writing center personnel will be best equipped to assist engineering faculty members and their students in their quest for better writing.

\section{References:}


[1] Clippinger, David C., Jernquist, Kathleen S., Nozaki, Stephen, "Improving Undergraduate STEM Writing through Common Language as Tool to Teach Engineering Dialects," Paper \& presentation, ASEE Annual Conference Proceedings 2019

[2] ABET Criteria for Accrediting Applied \& Natural Science Programs 2020-2021, ASAC, ABET Inc. 2020

[3] ABET Criteria for Accrediting Engineering Technology Programs, 2020-2021, ETAC, ABET Inc. 2020

[4] ABET Criteria for Accrediting Engineering Programs 2020-2021, EAC, ABET, Inc. 2020

[5] Boettger, Ryan K. and Wulff, Stefanie, "Using authentic language data to teach discipline-specific writing patterns to STEM students" IEEE International Professional Communication Conference (IPCC) Proceedings, 2016

[6] Wolfe, Joanna., "How Technical Communication Textbooks Fail Engineering Students", Technical Communication Quarterly, vol. 18, pp. 351-375, 2009

[7] Walker Kristen, "Integrating Writing Instruction into Engineering Courses: A Writing Center Model," Journal of Engineering Education, vol. 89 no. 3, pp. 369-375, 2000

[8] Poe, Mya, Lerner, Neal, and Craig, Jennifer Learning to Communicate in Science and Engineering: Case Studies from MIT, The MIT Press. Cambridge Massachusetts, pp. 18-27, 2010

[9] Leydens, J. A., "Novice and insider perspectives on academic and workplace writing: toward a curriculum of rhetorical awareness" IEEE Transactions of Professional Communication 50 (1), 45-46.

[10] Conrad, Susan, “A Comparison of Practitioner and Student Writing in Civil Engineering” 106(2), 191-217

[11] Beaufort, Anne, College Writing and Beyond: A New Framework for University Writing Instruction, Utah State, 2007

[12] Artemeva, Natasha, “'An Engrained Part of My Career': The Formation of a Knowledge Worker in the Dual Space of Engineering Knowledge and Rhetorical Process" Writing in Knowledge Societies, pp. 321-350, 2011

[13] Devitt, Amy., Writing Genres, Carbondale: Southern Illinois Press, 2004, pp. 1-32

[14] Swales, John M., Feak, Christine B., Academic Writing for Graduate Students: Essential Tasks and Skills, 3rd Edition, The University of Michigan, pp. 17-37, 2012 
[15] Kmiec, David and Longo, Bernadette, The IEEE Guide to Writing in the Engineering and Technical Fields IEEE Press Wiley, 2017

[16] Smit, David, The End of Composition Studies. Carbondale: Southern Illinois UP, 2007

[17] Bazerman, Charles, “'Genre and Cognitive Development” Genre in a Changing World Fort Collins, CO: Parlor Press, pp. 279-294, 2011

[18] Irish, Robert, Writing in Engineering: A Brief Guide. New York: Oxford UP, pp. 151-205, 2015 